\title{
Left Atrial Enlargement an Early Predictor for Development of Systolic Dysfunction - Results of a Cross-Sectional Study Conducted in Georgia
}

\author{
Eka Rukhadze, MD \\ Nino Tabagari-Bregvadze, $M D, P h D$ \\ Levan Tvildiani, $M D, P h D$ \\ David Tvildiani Medical University, Georgia
}

Doi: 10.19044/esj.2017.v13n33p1 URL:http://dx.doi.org/10.19044/esj.2017.v13n33p1

\begin{abstract}
Background and Aims: Left ventricular systolic dysfunction, even asymptomatic, is associated with the development of heart failure (HF) and all-cause mortality. Left ventricular ejection fraction (LVEF) is the most commonly used marker of left ventricular systolic function. It is well established that early detection and treatment of reduced LVEF, as well as the aggressive management of predisposing conditions, delays the manifestation of HF. Our study aimed to measure the association between LVEF and other echocardiographic variables in a population with LVEF within the normal range and without symptoms of HF. Methods: We conducted a cross-sectional study in 2008-2009. Results: We analyzed echocardiographic and clinical data of 146 patients: 66.4\% were women; mean age was 55 (40 -69 years). LVEF significantly correlated only with left atrium (LA) size (Beta -0.266, $\mathrm{p}<0.05$ ). The correlation was inverse and remained significant after adjusting for age, gender, obesity, diabetes, arterial hypertension, left ventricular hypertrophy, pulmonary systolic pressure, mitral regurgitation, and diastolic dysfunction. Conclusions: We found that the earliest structural change associated with LVEF tendency to decrease was LA size. Further research is needed to assess the LA enlargement as an early predictor of systolic dysfunction development.
\end{abstract}

Keywords: Echocardiography, Left Ventricular Systolic dysfunction, Ejection Fraction, Left Atrium

\section{Introduction}

Left ventricular systolic dysfunction, even asymptomatic, is a high risk for development of heart failure (HF), coronary vascular disease (CVD) and all-cause mortality [Yeboah J. et al., 2012, Abhayarantna W. P, 2012, 
Kardys I. et al., 2010, Reddy K et al., 2004]. The development of systolic dysfunction indicates the progression to the $\mathrm{C}$ stage of $\mathrm{HF}$ and predicts the occurrence of HF symptoms [Echouffo-Tcheugui JB, Erqou S, Butler J, Yancy CW, Fonarow GC., 2016, Echouffo-Tcheugui JB, Erqou S, Butler J, Yancy CW, Fonarow GC, 2015]. Left ventricular ejection fraction (LVEF ) is the most commonly used marker of left ventricular systolic function [Abhayarantna W. P, 2012, Carerj S, et al., 2010, Laure MS, Evans JC, Levy D, 1992]. Early detection and treatment of reduced LVEF, as well as the aggressive management of well-established predisposing conditions of $\mathrm{HF}$, delays the manifestation of HF [Echouffo-Tcheugui et al, 2016, Echouffo-Tcheugui et al, 2015, Nanayakkara S Kaye DM, 2015, Yusuf S, Pitt B, Davis CE, Hood WB Jr, Cohn JN, 1992].

The predisposing conditions of HF include CVD, smoking, arterial hypertension, obesity, diabetes, valvular heart disease, and male sex [He J et al., 2001, Baldasseroni S, et al., 2002].

Among patients, without HF symptoms traditional cardiovascular risk factors correlate with echocardiographic parameters [Rukhadze E, Bregvadze-Tabagari N, Tvildiani L, 2016, Kardys I. et al., 2010]. Echocardiography has an additional value in the prediction of $\mathrm{HF}$ progression and the development of cardiovascular events [Abhayarantna W. P, 2012, Carerj S, et al., 2010, Laure MS, Evans JC, Levy D, 1992].

This paper describes further analysis of the data collected as part of our study published in 2016 and 2017 [Rukhadze E, Bregvadze-Tabagari N, Tvildiani L, 2016] and between echocardiographic characteristics and the CVD risk groups defined by WHO (World Health Organization) /ISH (International Society of Hypertension) [Rukhadze E, Bregvadze-Tabagari N, Tvildiani L, 2017].

Our study aimed at measuring the association between LVEF and other echocardiographic variables in a population without symptoms of $\mathrm{HF}$ and preserved LVEF.

\section{Material and Method}

The population of our study is a subpopulation of a larger study [Shanthi M, 2005, Toidze M, Tabagari S, Mendis S, Norder P, BregvadzeTabagari N, Tvildiani L, Phkhaladze G, Talakvadze T, 2012]. We conducted a cross-sectional study in Sachkhere Medical Center in Georgia from September 2008 to December 2010. The study protocol was approved by the Sachkhere Medical Center and David Tvildiani Medical University Ethics committees. Participation was voluntary. All participants gave written informed consent.

The study group included 177 participants without clinically manifested cardiovascular disease, who underwent routine transthoracic 
echocardiography during the period of "Cardiovascular Risk Assessment of the Georgian Population study" [Toidze M et al., 2012]. We excluded 31 (17.5\%) participants from our analysis. For Exclusion we used the following criteria: LVEF < $50 \%$, severe valvular heart disease defined by European Association of Echocardiography (EAE) and American Society of Echocardiography (ASE) recommendations [ASE COMMITTEE RECOMMENDATIONS for Chamber Quantification, 2005], and atrial fibrillation.

Out of 146 participants included in the final statistical analysis, ??? $(66.4 \%)$ were women; mean age was 55 (40 -69 years).

\section{Assessment of CVD risk factors}

For hypertension we used Joint National Committee (JNC 7) definitions [ESC Committee for Practice Guidelines to improve the quality of clinical practice and patient care in Europe, 2007]; Hyperlipidemia was defined as fasting total cholesterol $\geq 5.2 \mathrm{mmol} / \mathrm{L}(\geq 200 \mathrm{mg} / \mathrm{dl})$; diabetes was defined as fasting glucose $\geq 7 \mathrm{mmol} / \mathrm{L}(\geq 126 \mathrm{mg} / \mathrm{dl}$ ) or use of insulin or oral hypoglycemic medications. Persons who smoked regularly during the previous 12 months were classified as smokers.

\section{Echocardiography assessment}

We performed Echocardiography on Philips Sonos 7500 with Secondary Harmonic Imaging by the recommended technique for transthoracic quantitative evaluations [ASE COMMITTEE RECOMMENDATIONS for Chamber Quantification, 2005].

We assessed the mean values and correlation of the following echocardiographic characteristics: left ventricular end-diastolic diameter (LVEDD), interventricular wall thickness (IWS), posterior wall thickness (PWT), left ventricular end-diastolic volume (LVEDV), left ventricular ejection fraction (LVEF), left atrium diameter (LAD), and pulmonary systolic pressure (PSP).

We evaluated Left ventricular systolic function by the method of discs (Simpson's rule) - using area tracings of the LV cavity [ASE COMMITTEE RECOMMENDATIONS for Chamber Quantification, 2005]. For the LA measure, we used LA anteroposterior linear dimension in the parasternal long-axis view by 2 Dimensional (2D) echocardiography [ASE COMMITTEE RECOMMENDATIONS for Chamber Quantification, 2005]. The PSP was assessed by continuous-wave Doppler of tricuspid regurgitation [Berger M, Haimowitz A, Van Tosh A, Berdoff RL, Goldberg E, 1985]. For assessment of left ventricular diastolic function, we analyzed mitral inflow patterns defined by pulsed wave (PW) Doppler. Additionally, in some cases, we used PW tissue Doppler (DTI) for assessment mitral 
annular early and late diastolic velocities [Recommendations for the Evaluation of Left Ventricular Diastolic Function by Echocardiography, 2009].

\section{Statistical Analysis}

We analyzed the data using IBM SPSS Statistics version 21. Descriptive statistics (means, standard deviations, and proportions) were calculated for cardiovascular risk factors and echocardiographic characteristics. Linear regression method was used to establish correlations between EF and other echocardiographic variables. A p-value <0.05 was defined as statistically significant.

\section{Results}

Our study p opulation is described in table 1.

Most of our participants were women; age varied from 40 to 69 (mean age 55). Obesity (OB) was present in $56.80 \%$ of study population; Diabetes Mellitus (DM) (12.30\%); Hyperlipidemia (19.20\%); Smoking (11.60\%); Arterial hypertension (47.30\%).

Table 1. Demographic, Clinical and Echocardiographic Characteristics $(\mathrm{N}=146)$

\begin{tabular}{l|l} 
Characteristic & Count (\%) \\
Women & $97(66.4)$ \\
Obesity & $93(56.8)$ \\
Diabetes Mellitus & $18(12.3)$ \\
Hyperlipidemia & $28(19.2)$ \\
Smoking & $17(11.6)$ \\
Arterial Hypertension & $69(47.3)$ \\
LVH & $7(4.8)$ \\
DF (impaired relaxation / pseudonormal) & $124(84.9)$ \\
MR (1st degree / 2nd degree) & $146(94.5)$ \\
& Mean (SD) \\
Age, year & $54.75(8.9)$ \\
IVS (mm) & $10.4(1.5)$ \\
PWT (mm) & $10.3(1.5)$ \\
LA diameter (mm) & $40.8(4.5)$ \\
PSP (mmHg) & $28.3(9.5)$ \\
LVD (mm) & $48.9(4.6)$ \\
LVEDV (ml) & $102.2(24.7)$ \\
LVEF (\%) & $61.5(4.9)$
\end{tabular}

LA, Left atrium diameter; LVD, Left ventricular end-diastolic dimension; IVS, Interventricular septum thickness; PWT, Left ventricular posterior wall thickness; LVEDV, Left ventricular end-diastolic volume; LVEF, Left ventricular ejection function; PSP, Pulmonary Systolic Pressure; MR, Mitral regurgitation; DF, Diastolic function, LVH, Left ventricular hypertrophy. 
Mean values of all evaluated echocardiographic variables (LVD, IVS, LVEDV, PSP and EF) except LA were in the normal range, while LA diameter was slightly increased (normal value $<40 \mathrm{~mm}$ ). Left ventricular Hypertrophy (LVH) defined by left ventricular wall thickness was present only in $4.8 \%$ of study population. Left ventricular diastolic dysfunction (impaired relaxation and pseudonormal type) was presented in $84.9 \%$ of the study population, mitral regurgitation (first and second degree $-94.5 \%$.

In table 2 is represented the correlation between LVEF and some of the traditional CVD risk-factors and echocardiography characteristics. The LVEF significantly correlated only with LA diameter (inverse correlation). This correlation remains significant (Beta $-0.266, \mathrm{p}<0.05$ ) after adjusting for age, gender and presence or absence Obesity, Diabetes Mellitus, Arterial Hypertension and echocardiography defined left ventricular hypertrophy, Pulmonary Systolic pressure, and presence or absence mitral regurgitation and diastolic dysfunction.

Table 2. Correlation of LVEF with CVD risk-factors and echocardiography characteristics.

\begin{tabular}{|c|c|c|}
\hline Characteristics & Beta & $\mathrm{p}$-value \\
\hline LA & $-0,266$ & 0,032 \\
\hline Age & $-0,054$ & 0,572 \\
\hline Gender & 0,060 & 0,498 \\
\hline Obesity & 0,027 & 0,756 \\
\hline Diabetes Mellitus & $-0,067$ & 0,436 \\
\hline Arterial Hypertension & $-0,094$ & 0,283 \\
\hline LVH & 0,039 & 0,654 \\
\hline Hyperlipidemia & 0,042 & 0,627 \\
\hline MR & 0,014 & 0,900 \\
\hline DF & 0,115 & 0,317 \\
\hline PSP & $-0,111$ & 0,265 \\
\hline
\end{tabular}

LA, Left atrium diameter; LVD, LVEF, Left ventricular ejection function; PSP, Pulmonary Systolic Pressure; MR, Mitral regurgitation; DF, Diastolic function, LVH, Left ventricular hypertrophy.

\section{Discussion}

Our study revealed there is a strong correlation between LA size and EF in a population without any clinical presentation of HF, with a slightly increased mean LA size, but a reserved mean EF. The correlation remains significant after adjusting for age, echocardiography evaluated $\mathrm{LVH}$, the presence of Diabetes Mellitus and Obesity. As it was mentioned in our previous studies, LA was the echocardiographic variable that correlated with most CVD risk factors (age, BMI, WC, SBP, and TCH). Age and obesity variables (WC and BMI) correlated with most of the echocardiographic characteristics [Rukhadze E, Bregvadze-Tabagari N, Tvildiani L, 2016]; In 
different WHO-ISH risk groups, statistically significant differences were established for LA, PSP, and EF: LA and PSP increased from low to highrisk groups, while EF decreased, but remained in normal range.

It means LA enlargement is a more sensitive marker than EF reduction, can occur earlier, and may be considered as an early predictor of systolic dysfunction.

The prognostic role of left atrial enlargement was the subject of several recent studies. The role of LA volume as a marker for severity and as a significant independent predictor of LV diastolic dysfunction is well established [Paulus WJ et al, 2007, Lim TK, Ashrafian H, Dwivedi G, Collinson PO, Senior R, 2006, Douglas PS, 2003, Tsang TS, Barnes ME, Gersh BJ, Bailey KR, Seward JB, 2002]. There are also studies which revealed that LA size and volume are as strong a predictor of death and other cardiovascular events in a general population as in patients with a variety of cardiac diseases [Bombelli M et al, 2014, Rossi A et al, 2009, Patel D, Lavie C, Milani, R, Shah S, Gilliland Y, 2009, Laukanen JA, Kurl S, Eranen J, Huttunen M, Salonen JT, 2005, Rossi A et al, 2002, Rossi A et al 2000].

According to the results of PAMELA study, which estimated the risk of cardiovascular events, cardiovascular mortality, and all-cause mortality associated with the LA enlargement alone or combined with echocardiographic LVH in 1,785 representatives of the general population, subjects with isolated LA enlargement exhibited a significant increase in the adjusted risk of combined fatal and nonfatal cardiovascular events [Bombelli M et al, 2014].

Similar results were obtained in CARDIA study, which included young adults above the clinically established Framingham 10-year global $\mathrm{CV}$ risk score. The combined endpoint (incident fatal or nonfatal cardiovascular disease: myocardial infarction, heart failure, cerebrovascular disease, peripheral artery disease, atrial fibrillation/flutter) was determined after 20 years. LA size measurements independently predicted the clinical outcomes, but without altering risk classification [Armstrong A et al., 2014].

We can conclude LA enlargement can be considered an early predictor of reducing EF and thus developing systolic dysfunction. Further studies needed to assess the cost effectiveness of routine echocardiographic examination of patients without clinical manifestation of HF. In patients with increased LA size, but otherwise normal structural echocardiographic parameters, risk modification should be more aggressive to delay the manifestation of HF. Additional study is needed to confirm our hypothesis. 


\section{References:}

1. Yeboah J, Rodriguez CJ, Stacey B, Lima JA, Liu S, Carr JJ, Hundley WG, Herrington DM. Prognosis of individuals with asymptomatic left ventricular systolic dysfunction in the multi-ethnic study of atherosclerosis (MESA). Circulation. 2012 Dec;126 (23):2713-9. Epub 2012 Nov 2.

2. Abhayarantna W. P., Echocardiography for the "Superior Doctor" A Call to Action in the Management of Heart Failure, J am Cardiol. Img. 2012.5 (2) 141-143

3. Reddy K, Koshy S, Wasson S, Aggarwal K, Tejwani L, Ovechkin A, Tyagi $\mathrm{S}$.

4. Echocardiography predicts adverse cardiac remodeling in heart failure, Clin Cardiol Vol 9 No 22004

5. Carerj S, La Carrubba S, Antonini-Center F, Di Salvo G, Erlicher A, Liguori E, Monte I, Badano L, Pezzano A, Caso P, Pinto F, Di Bello V; Research Group of the Italian Society of Cardiovascular Echography, The incremental prognostic value of echocardiography in asymptomatic stage a heart failure. J Am Soc Echocardiogr. 2010 Oct; 23 (10): 1025-34

6. Laure MS, Evans JC, Levy D. Prognostic implications of subclinical left ventricular dilatation and systolic dysfunction in men free of overt cardiovascular disease (the Framingham Heart Study). Am J Cardiol. -21.1992;70:1180-4

7. Echouffo-Tcheugui JB, Erqou S, Butler J, Yancy CW, Fonarow GC.

8. Assessing the Risk of Progression From Asymptomatic Left Ventricular Dysfunction to Overt Heart Failure: A Systematic Overview and Meta-Analysis., JACC Heart Fail. 2016 Apr;4(4):23748. Epub 2015 Dec 9.

9. Echouffo-Tcheugui JB, Erqou S, Butler J, Yancy CW, Fonarow GC, Assessing the Risk of Progression From Asymptomatic Left Ventricular Dysfunction to Overt Heart Failure: Systematic Overview and Meta-Analysis., JACC Heart Fail. 2016 Apr;4(4):237-48. Epub 2015 Dec 9.

10. Nanayakkara S Kaye DM. Management of heart failure with preserved ejection fraction: a review. Clin Ther. 2015 Oct 1;37(10):2186-98. doi: 10.1016/j.clinthera.2015.08.005. Epub 2015 Sep 16.

11. Yusuf S, Pitt B, Davis CE, Hood WB Jr, Cohn JN Effect of enalapril on mortality and the development of heart failure in asymptomatic patients with reduced left ventricular ejection fractions. SOLVD Investigators, N Engl J Med. 1992;327(10):685. 
12. He J, Ogden LG, Bazzano LA, Vupputuri S, Loria C, Whelton PK. Risk factors for congestive heart failure in US men and women: NHANES I epidemiologic follow-up study. Arch Intern Med. 2001;161(7):996.

13. Baldasseroni S, Opasich C, Gorini M, Lucci D, Marchionni N, Marini M, Campana C, Perini G, Deorsola A, Masotti G, Tavazzi L, Maggioni AP, Italian Network on Congestive Heart Failure Investigators. Left bundle-branch block is associated with increased 1-year sudden and total mortality rate in 5517 outpatients with congestive heart failure: a report from the Italian network on congestive heart failure. Am Heart J. 2002;143(3):398

14. Rukhadze E, Bregvadze-Tabagari N, Tvildiani L. Association of Echocardiographic Characteristics with Cardiovascular Risk Factors in Adults without Clinical Manifestation of Heart Failure, Georgian Medical News, N 10 (259) 2016:36-41

15. Kardys I., Deckers JW, Stricker B, Vetter W, Hofman A, Witteman J. Distribution of echocardiographic parameters and their associations with cardiovascular factors in the Rotterdam Study, Eur J Epidemiol (2010) 25:481-490

16. Rukhadze E, Bregvadze-Tabagari N, Tvildiani L. Echocardiographic characteristics of different WHO/ISH Cardiovascular disease risk groups, Georgian Medical News, N 6 (267) 2017:65-71

17. Shanthi Mendis. Cardiovascular risk assessment and management in developing countries. Vascular Health and risk Management 2005:1(1) 15-18

18. Toidze M, Tabagari S, , Mendis S, Norder P, Bregvadze-Tabagari N, Tvildiani L, Phkhaladze G, Talakvadze T. Risk Factors of Cardiovascular Disease and Cardiovascular Risk Assessment of The Georgian Population By WHO/ISH Risk Assessment Scores. J Innovative Medicine and Biology N1-2 2012; 8:24

19. Recommendations for Chamber Quantification: A Report from the American Society of Echocardiography's Guidelines and Standards Committee and the Chamber Quantification Writing Group, Developed in Conjunction with the European Association of Echocardiography, a Branch of the European Society of Cardiology Members of the Chamber

20. Members of the Chamber Quantification Writing Group are: Roberto M. Lang, MD, FASE, Michelle Bierig, MPH, RDCS, FASE, Richard B. Devereux, MD, Frank A. Flachskampf, MD, Elyse Foster, MD, Patricia A. Pellikka, MD, Michael H. Picard, MD, Mary J. Roman, MD, James Seward, MD, Jack S. Shanewise, MD, FASE, Scott D. Solomon, MD, Kirk T. Spencer, MD, FASE, Martin St John Sutton, 
MD, FASE, and William J. Stewart, MD. Journal of the American Society of Echocardiography Volume 18 Number 12, 2005

21. ESC GUIDELINES DESK REFERENCE. ESC Committee for Practice Guidelines to improve the quality of clinical practice and patient care in Europe. COMPENDIUM OF ESC GUIDELINES 2007; 17-19

22. Berger M, Haimowitz A, Van Tosh A, Berdoff RL, Goldberg E. Quantitative assessment of pulmonary hypertension in patients with tricuspid regurgitation using continuous wave Doppler ultrasound, J Am Coll Cardiol. 1985 Aug;6(2):359-65

23. Paulus WJ, Tschöpe C, Sanderson JE, Rusconi C, Flachskampf FA, Rademakers FE, Marino P, Smiseth OA, De Keulenaer G, LeiteMoreira AF, Borbély A, Edes I, Handoko ML, Heymans S, Pezzali N, Pieske B, Dickstein K, Fraser AG, Brutsaert DL. How to diagnose diastolic heart failure: a consensus statement on the diagnosis of heart failure with normal left ventricular ejection fraction by the Heart Failure and Echocardiography Associations of the European Society of Cardiology. Eur Heart J. 2007;28(20):2539-2550.

24. Lim TK, Ashrafian H, Dwivedi G, Collinson PO, Senior R. Increased left atrial volume index is an independent predictor of raised serum natriuretic peptide in patients with suspected heart failure but normal left ventricular ejection fraction: implication for diagnosis of diastolic heart failure. Eur J Heart Fail. 2006;8(1):38-45.

25. Douglas PS. The left atrium: a biomarker of chronic diastolic dysfunction and cardiovascular risk. J Am Coll Cardiol. 2003;42(7):1206-1207.

26. Tsang TS, Barnes ME, Gersh BJ, Bailey KR, Seward JB. Left atrial volume as a morphophysiologic expression of left ventricular diastolic dysfunction and relation to cardiovascular risk burden. Am J Cardiol. 2002;90(12):1284-1289

27. Bombelli M, Facchetti R, Cuspidi C, Villa P, Dozio D, Brambilla G, Grassi G, Mancia G. Prognostic significance of left atrial enlargement in a general population: results of the PAMELA study. Hypertension 2014;64:1205-11

28. Patel D, Lavie C, Milani, R, Shah S, Gilliland Y. Clinical Implications of Left Atrial Enlargement: A Review. Ochsner J. 2009 Winter; 9(4): 191-196.

29. Laukanen JA, Kurl S, Eranen J, Huttunen M, Salonen JT. Left atrium size and risk of cardiovascular death in middle-aged men. Arch Intern Med. 2005;165:1788-93

30. Rossi A, Temporelli PL, Quintana M, Dini FL, Ghio S, Hillis GS, Klein AL, Marsan NA, Prior DL, Yu CM, Poppe KK, Doughty RN, 
Whalley GA; MeRGE Heart Failure Collaborators Independent relationship of left atrial size and mortality in patients with heart failure: an individual patient meta-analysis of longitudinal data (MeRGE Heart Failure). Eur J Heart Fail. 2009 Oct;11(10):929-36. doi: 10.1093/eurjhf/hfp112.

31. Rossi A Cicoira M Zanolla L Sandrini R Golia G Zardini P Enriquez Sarano M Determinants and prognostic value of left atrial volume in patients with dilated cardiomyopathy J Am Coll Cardiol 20024014 25

32. Rossi A Tomaino M Golia $G$ Anselmi $M$ Fucá $G$ Zardini $P$ Echocardiographic prediction of clinical outcome in medically treated patients with aortic stenosis Am Heart J 2000140766771

33. Armstrong AC, Liu K, Lewis CE, Sidney S, Colangelo LA, Kishi S, Ambala-Venkatesh B, Arynchyn A, Jacobs DR Jr, Correia LC, Gidding SS, Lima JA.. Left atrial dimension and traditional cardiovascular risk factors predict 20-year clinical cardiovascular events in healthy young adults: the CARDIA study, Eur Heart $\mathbf{J}$ Cardiovasc Imaging. 2014 Aug;15(8):893-9. doi: 10.1093/ehjci/jeu018. Epub 2014 Feb 16 